\title{
ESTRUTURA INTELECTUAL DA PRODUÇÃO CIENTÍFICA SOBRE PROPENSÃO AO EMPREENDEDORISMO: UMA ANÁLISE À LUZ DAS COCITAÇÕES
}

\author{
THE INTELLECTUAL STRUCTURE OF SCIENTIFIC PRODUCTION ON ENTREPRE- \\ NEURIAL PROPENSITY: AN ANALYSIS IN THE LIGHT OF CO-CITATIONS
}

\author{
Recebido em: 19/03/2018 • Aprovado em: 27/06/2018 \\ Avaliado pelo sistema double blind review \\ Editor Científico: Edson Sadao Iizuka \\ DOI 10.13058/raep.2018.v19n3.1047
}

\section{LORENI MARIA DOS SANTOS BRAUM lorenibraum@hotmail.com VÂNIA MARIA JORGE NASSIF}

UNIVERSIDADE NOVE DE JULHO

\section{RESUMO}

A propensão ao empreendedorismo consiste na predisposição favorável do indivíduo para a criação de novos empreendimentos. Este trabalho pretende apresentar a estrutura da produção científica que serve de alicerce para os estudos referentes à propensão ao empreendedorismo, por meio da análise de cocitações. O método utilizado foi exploratório e os dados para as análises foram constituídos de artigos científicos, recuperados na base Scopus. Os resultados revelaram que os referidos estudos tiveram início na década de 70, embora só a partir de 2000 tenha ocorrido um aumento significativo destes. A Análise Fatorial Exploratória (AFE) revelou que a estrutura da produção científica sobre propensão ao empreendedorismo é explicada em 68,34\% por 24 autores, os quais o agrupou em oito dimensões: empreendedorismo como processo organizacional; características do empreendedor; atitude e comportamento empreendedor; antecedentes da intenção empreendedora; lócus de controle e efeitos da cultura no empreendedorismo; processos cognitivos e identificação de oportunidades; ação empreendedora; e tomada de decisão. Este estudo corrobora a necessidade de continuidade de investigações visando a busca de um núcleo para entender o papel desempenhado pelo empreendedor na sociedade. Futuras pesquisas poderiam explorar semelhanças e diferenças entre os constructos presentes na literatura atual sobre futuros empreendedores.

Palavras-chave: Estrutura da produção científica, Propensão ao empreendedorismo, Análise de cocitações.

\footnotetext{
ABSTRACT

Entrepreneurial propensity is the favorable predisposition of the individual to create new ventures. This study aimed to present the structure of the scientific production that provides the basis for studies on the tendency to entrepreneurship, using co-citation analysis. The method was exploratory and the data analysis was performed on scientific articles retrieved from the Scopus database. The results revealed that studies on the topic began in the 1970s, but it was only after the year 2000 that a significant increase in research occurred. Exploratory Factorial Analysis (EFA) revealed that the structure of scientific production on a propensity for entrepreneurship is explained in $68.34 \%$, by 24 authors, who were grouped in eight dimensions: entrepreneurship as an organizational process; the characteristics of entrepreneurs; entrepreneurial attitudes and behavior; the antecedents of entrepreneurial intention; locus of control and effects of culture on entrepreneurship; cognitive processes and identification of opportunities; entrepreneurial action and decision making. This study reinforces the need for more investigations that aim to find a nucleus to understand entrepreneurs' importance in society. Future research could explore similarities and differences between the constructs present in the current literature about future entrepreneurs.

Keywords: structure of scientific production, propensity for entrepreneurship, co-citation analysis.
} 


\section{INTRODUÇÃO}

As pesquisas sobre empreendedorismo têm avançado em direção de diferentes áreas de estudos, tais como: características psicológicas do empreendedor, estratégias de sucesso e causas de insucesso, oportunidades de novos negócios e influência dos fatores ambientais, sociais e econômicos acerca da ação empreendedora. Estas pesquisas podem ser agrupadas em, pelo menos, cinco categorias: definição da palavra empreendedorismo, características psicológicas dos empreendedores, estratégias de sucesso tanto em novos empreendimentos quanto naqueles já existentes, exploração de oportunidades de novos negócios e estudo dos efeitos de fatores ambientais sobre as ações empreendedoras (BULL; WILLARD, 1993). Embora a pesquisa destes autores seja da década de 90 , esta classificação permanece vigente na literatura.

Para a melhor compreensão do fenômeno empreendedorismo é necessário considerar não apenas o processo de criação de negócios; exigências em relação à dedicação de tempo e esforço necessários para a criação e a operacionalização de algo novo; as implicações da assunção de riscos (financeiros, psicológicos e sociais); como também as recompensas e retornos conquistados (satisfações pessoal e econômica) (HISRICH, 2004). Assim sendo, o empreendedorismo pode ser entendido como "o processo de criar algo novo, com valor dedicando o tempo e os esforços necessários, assumindo os riscos financeiros, psíquicos e sociais correspondentes e recebendo as consequentes recompensas da satisfação e independência econômica e pessoal" (HISRICH, 2004, p. 29). Neste sentido, seis elementos são essenciais para a compreensão do empreendedorismo: inovação, reconhecimento de oportunidades, ação, gestão de risco, uso de recursos e valor agregado (FILION, 2011).

Sob a perspectiva de Shane e Venkataraman (2000), o empreendedorismo compreende um processo de descoberta, evolução e exploração de oportunidades, concretizando-se por meio da inovação e criatividade contínuas. Diferentes características, entre as quais, a autoeficácia e a assunção de riscos, vêm sendo alvo de estudos que buscam relacioná-las com 
a intenção de empreender. Moraes, Iizuka e Pedro (2018), por exemplo, desenvolveram e validaram um modelo para explicar a intenção empreendedora por meio de três aspectos: autoeficácia, influenciada pela sociabilidade, liderança, planejamento e inovação; assunção de riscos; e ambiente universitário. Os resultados do estudo desses autores evidenciaram que os aspectos mencionados foram considerados influenciadores diretos da intenção empreendedora. Além disso, o poder de explicação do modelo foi de $\mathrm{R}^{2} 0,424$.

A compreensão dos fatores que conduzem os indivíduos ao empreendedorismo tem se revelado um tema de peso para as pesquisas científicas realizadas (JOHNSON; FREEMAN; STAUDENMAIER, 2015). No entanto, embora sejam identificadas diversas pesquisas tratando das características individuais dos empreendedores, tais como: necessidade de realização e o locus de controle interno - propensão para correr riscos (BROCKHAUS, 1982), visão, desejo pela independência, paixão e ação (Shane et al., 2003; SHANE; VENKATARAMAN, 2000), criatividade, inovação e, a assunção de riscos (SHANE; VENKATARAMAN, 2000; STEWART; e ROTH, 2001; MOROZ; HINDLE, 2012), ainda são escassas as pesquisas concernentes à propensão ao empreendedorismo como uma predisposição do indivíduo para criar novos negócios.

Diante desta constatação surge o seguinte questionamento: Como está estruturada a produção científica que fornece o embasamento teórico para estudos sobre a propensão ao empreendedorismo? Buscando respondê-la, o presente estudo teve por objetivo analisar a estrutura intelectual da produção científica que fornece a base para os estudos relacionados à propensão ao empreendedorismo, por meio da análise de cocitações.

Desse modo, a propensão para a ação refere-se a uma predisposição pessoal para agir em suas decisões, refletindo-se no componente que exprime as intenções (SHAPERO; SOKOL, 1982). Partindo deste pressuposto e das definições apresentadas por Chelariu et al. (2008), Khanduja e Kaushik (2009) e Brazeal (1993), a propensão ao empreendedorismo para fins do presente estudo é a predisposição favorável de um individuo para criar novos empreendimentos, sem necessariamente considerar as adversidades futuras, refletin- 
do, um sentimento favorável que ainda não chega a ser a intenção de empreender, mas poderá tornar-se futuramente.

Para a coleta dos dados foi usada a base de dados Scopus em que foram identificadas 367 publicações com o seguinte termo de busca: Entrepreneurial or Entrepreneurship e Propensity, nas quais foram analisadas as cocitações das publicações. O Bibexcel foi utilizado na organização dos dados para a análise bibliométrica e o SPSS realizou a Análise Fatorial Exploratória (AFE), cuja finalidade residiu em verificar o padrão de correlações existentes entre as variáveis e utilizá-lo para agrupar as variáveis em fatores (HAIR et al., 2009).

Sob essas perspectivas, este estudo traz as seguintes contribuições: em relação às produções acadêmicas da área, apresenta os resultados das investigações realizadas abrindo oportunidades de estudos mais específicos e objetivos, visando a ampliação do conhecimento da área, além de mostrar lacunas de estudos ainda não elaborados, os quais servirão para alargar mais ainda o conhecimento do tema. Conforme Lopes (2012), as publicações científicas apresentam a evolução dos estudos, em um determinado período, a partir dos autores clássicos do tema.

A escolha por um tema específico em um trabalho científico, neste caso, propensão ao empreendedorismo, contribui com o conhecimento mais expressivo do constructo, especialmente quando realizado por meio da bibliometria. Neste sentido, é possível observar outros constructos que se relacionam com o objeto de análise, pois a bibliometria oferece, quantitativa e estatisticamente, os índices da produção em estudo, a avaliação e a interlocução entre indivíduos, instituições e áreas de pesquisa (LOPES et al., 2012; RODRIGUES, 1982)

Outra importante contribuição deste estudo volta-se para a análise de cocitação, desenvolvida por Small (1973) e McCain (1991) em conjuntos de periódicos, e White e Griffith (1991) voltado para os autores, evidenciando a frequência de relacionamento entre autores, proporcionando uma melhor compreensão acerca da proximidade temática e, assim, da estrutura intelectual da produção científica do constructo em estudo (SMIRAGLIA, 2011). Essas contribuições, além de abrirem caminhos para novas investiga- 
ções, oferecem aos pesquisadores a oportunidade de aprofundarem o tema de suas pesquisas nas vertentes conceituais e metodológicas.

Cabe destacar que, neste estudo, a estrutura intelectual da produção científica sobre propensão ao empreendedorismo é entendida como sendo a estrutura visualizada a partir do grau de similaridade de conteúdo (tema de pesquisa), a qual ao ser reunido em agrupamentos (dimensões) exibe as relações estruturais de conectividade teórico-metodológica do tema, a proximidade e as interconexões deste campo de domínio científico.

Quanto à estrutura deste estudo, além desta introdução, apresentam-se aspectos gerais sobre o empreendedorismo e a análise da produção científica. Em seguida, a metodologia adotada para a seleção das publicações. Posteriormente, apresenta a análise das cocitações contidas nas publicações apresentando a base teórica para os estudos pertinentes à propensão ao empreendedorismo, por meio da Análise Fatorial Exploratória e, por fim, as considerações finais e sugestões para futuras pesquisas. 


\section{FUNDAMENTAÇÃO TEÓRICA}

Nesta seção são apresentados os aspectos relacionados ao empreendedorismo e a análise da produção científica.

\section{EMPREENDEDORISMO}

O empreendedorismo pode ser visto como um processo de inovação independente no qual um empreendedor, buscando criar algo novo, combina características pessoais como alta motivação e capacidade de visualizar novas oportunidades com a disposição para ser criativo e correr riscos, inclusive diante de incertezas e mudanças frequentes na economia (STEWART; WATSON; CARLAND; CARLAND, 1999). Trata-se de um fenômeno complexo composto por uma série de ações que envolve características técnicas, humanas, gerenciais e empresariais, cujo desempenho exige um conjunto diversificado de competências (FILION, 2011).

A natureza do empreendedorismo é norteada por sete perspectivas: geração de riqueza - cujo empreendedorismo consiste em assumir os riscos associados com a atividade produtiva em troca de lucro; criação de empresa - em que o empreendedorismo requer a criação de um novo negócio em um local onde não existia antes nenhum desse tipo; geração de inovação o empreendedorismo tem a preocupação com combinações, sem igual, de recursos que farão os métodos ou produtos existentes ficarem obsoletos; geração de mudança - cujo empreendedorismo refere-se o planejamento de mudanças ajustando, adaptando e modificando o repertório pessoal, abordagens e habilidades, para encontrar as oportunidades diferentes disponíveis no ambiente; geração de emprego - no qual o empreendedorismo tem a preocupação com emprego, administração e desenvolvimento dos fatores de produção, inclusive da força de trabalho; criação de valor - em que empreendedorismo é um processo de criação de valor para os clientes, utilizando oportunidades não exploradas; e, geração de crescimento - o empreendedorismo pode ser definido como uma orientação forte e positiva para o crescimento em vendas, renda, recursos e empregos (MORRIS; LEWIS; SEXTON, 1994, p. 21-29). 
Os economistas trouxeram avanços significativos para os estudos relacionados ao empreendedorismo. No entanto, a ênfase esteve centrada na função do empreendedor no contexto econômico e diversos questionamentos acerca dos comportamentos dos indivíduos empreendedores não foram considerados. McClelland (1961) foi um dos pioneiros no uso de teorias comportamentais com o intuito de estudar a motivação para empreender, buscando estabelecer uma ligação entre a necessidade de realização e o desenvolvimento econômico de determinadas sociedades. Yasin (1996) sumarizou o arcabouço teórico para o desenvolvimento econômico proposto por McClelland como sendo uma sequência de acontecimentos, que se originam no protestantismo e seus valores; passando pelo treinamento realizado com crianças, de forma independente ou controlada pelos pais; desenvolvimento de alta necessidade realização nas crianças; e, por consequência, o desenvolvimento do desejo de sucesso, o florescimento do espírito empreendedor na sociedade, culminando com o crescimento econômico da nação. Em seus estudos McClelland (1961), concluiu que nas sociedades onde se teve alta necessidade de realização houve crescimento econômico, assim, seus estudos são clássicos e têm como enfoque central a associação entre a necessidade de realização e o crescimento econômico.

Na perspectiva de McClelland (1961, p. 65), “um empreendedor é alguém que exerce o controle sobre os meios de produção e produz mais do que ele pode consumir e em decorrência vende (ou troca) essa produção objetivando renda pessoal ou familiar". O processo empreendedor pode ser resumido em uma sequência de passos em que, diante da existência de uma oportunidade, o indivíduo, em função de suas características e habilidades pessoais e da forma que atua no ambiente, decide explorar esta oportunidade abrindo possibilidade para buscar recursos necessários, estabelecer a estratégia do empreendimento, organizar o processo e depois executar o projeto (SHANE, 2003).

As características individuais ou traços pessoais são amplamente estudados quando se procura entender a ação de empreender. No entanto, Gartner (1988) considera que elas referem-se apenas a uma parcela no processo de empreendedorismo, uma vez que a ação empreendedora é multi- 
facetada e influenciada por vários fatores. Hisrich e Peters (2004) destacam que o processo de empreender ocorre por meio do esforço e da utilização do tempo que for necessário, para criar algo novo, com valor agregado, sendo que neste processo estão envolvidos os riscos (financeiros, psíquicos e sociais) e recompensas, manifestadas em forma de satisfação e independência (econômica e social).

Entre as contribuições relevantes para o campo do empreendedorismo encontra-se a Teoria do Comportamento Planejado, proposta por Ajzen (1991), responsável por ligar as crenças e o comportamento com o objetivo de explicar o comportamento das pessoas. A Teoria do Comportamento Planejado, conforme explica Ajzen (2002), pressupõe que a ação humana é baseada em três tipos de crenças: crenças sobre os prováveis resultados do comportamento (comportamentais), crenças sobre as expectativas de outros e a motivação para atender a essas expectativas (normativas) e crenças sobre a presença de fatores que podem facilitar ou dificultar o desempenho do comportamento, bem como a percepção da capacidade de desempenhar esse comportamento (controle). A Figura 1 apresenta o fluxo comportamental proposto nesta teoria.

Figura 1 Teoria do Comportamento Planejado

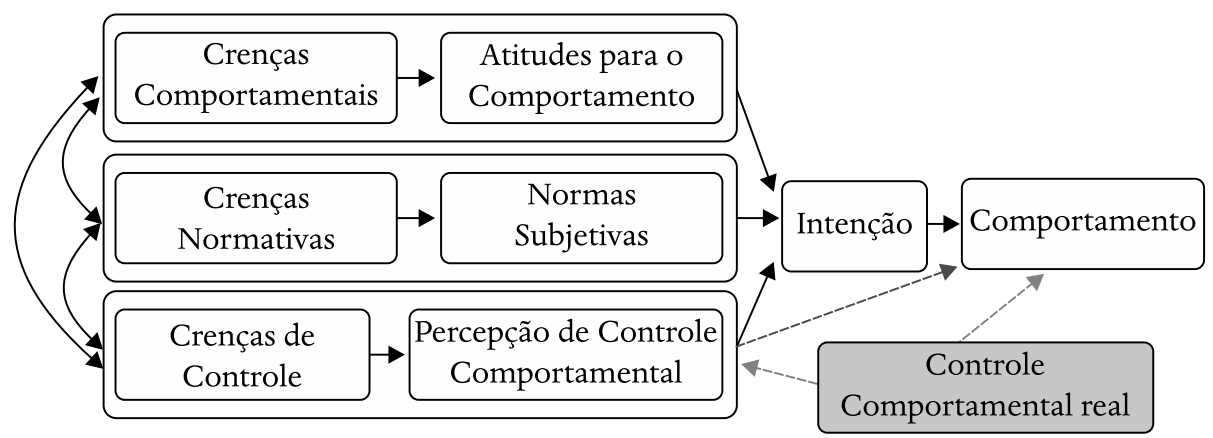

Fonte: Ajzen (2002, p. 1)

A combinação entre a atitude e o comportamento, a norma subjetiva e a percepção de controle comportamental conduzirão à intenção, a qual é uma preditora do comportamento (AJZEN, 2002). Filion recorrendo 
a autores clássicos, ressalta que, para uma definição do empreendedor, é necessário levar em conta seis componentes principais: inovação, reconhecimento de oportunidade, gestão de riscos, ação, utilização dos recursos e valor agregado. "Um empreendedor é um ator que inova, reconhecendo oportunidades; ele ou ela toma decisões moderadamente arriscadas que levam a ações que exigem o uso eficiente dos recursos e contribuem com um valor agregado." (FILION, 2011, p. 8).

As duas principais perspectivas do empreendedorismo (econômica e comportamental) surgem a partir da inovação, pois empreendedores inovam (DRUCKER, 1998). Ao ser considerado um fenômeno complexo caracterizando-se como o processo de descoberta, evolução e exploração de oportunidades, o empreendedorismo se concretiza por meio da inovação e criatividade contínuas (SHANE; VENKATARAMAN, 2000). Dentre os elementos essenciais estão: inovação, reconhecimento de oportunidades, ação, gestão de risco, uso de recursos e valor agregado (FILION, 2011). Entre as características individuais dos empreendedores salientam-se a necessidade de realização e o locus de controle interno, ou seja, a propensão para correr riscos (Brockhaus, 1982), a visão, o desejo pela independência, a paixão e a ação (SHANE et al., 2003).

A Propensão ao Empreendedorismo refere-se à inclinação ou tendência para o autoemprego (CHAVAN; TASKA, 2017) demonstrando "a predisposição favorável de um indivíduo para criação de novos empreendimentos" (CHELARIU et al., 2008, p. 406). A predisposição para a ação é um antecedente da intenção (SHAPERO; SOKOL, 1982; KRUEGER; REILLY; CASRUD, 2000; SUŠANJ; JAKOPEC; MILJKOVIĆ KREČAR, 2015). As intenções, por sua vez, são preditoras da ação de empreender (KRUEGER; BRAZEAL, 1994).

Shapero e Sokol (1982) foram os primeiros estudiosos da Teoria da Intenção Empreendedora e desenvolveram um modelo de mensuração denominado Entrepreneurial Event (SEE) tendo como objeto central a dimensão social do empreendedorismo. Dessa maneira, afirmam que o evento empreendedor (nascimento de um empreendedor) é a unidade de interesse especialmente em razão dos problemas referentes à definição de quem é ou 
não é um empreendedor em comparação com outros indivíduos. O evento empreendedor compreende cinco características: iniciativa, consolidação de recursos, gestão da organização, autonomia relativa e assunção de risco, assim, nesta abordagem, o evento empreendedor poderia referir-se à formação de um novo negócio (SHAPERO; SOKOL, 1982).

\section{ANÁLISE DA PRODUÇÃO CIENTÍFICA}

"A ciência é um empreendimento preocupado exclusivamente, com o conhecimento e a compreensão de fenômenos naturais." (KERLINGER, 1980). Nesse viés, o conhecimento pode ser popular, filosófico, religioso (teológico) e científico (TEOPHILO, 1998). Segundo este autor, o que diferencia o conhecimento científico dos outros tipos é a forma pela qual este é obtido. Os cientistas têm como objetivo central conhecer os fenômenos (KERLINGER, 1980), portanto, a ciência desempenha um papel estratégico nas transformações estruturais socioeconômicas, por isso, no cenário contemporâneo torna-se indispensável para o desenvolvimento tanto no âmbito nacional quanto mundial (MACHADO, 2015).

Sob essa ótica, a bibliometria faz uso de técnicas quantitativas e estatísticas para quantificar a produção científica contribuindo para desenvolver a ciência (MEDEIROS; VITORIANO, 2015), pois propicia o mapeamento e a geração de diferentes indicadores para tratar e gerenciar as produções científicas (GUEDES; BORSCHIVER, 2005). Originalmente a bibliometria foi denominada "bibliografia estatística", termo adotado por Hulme, em 1923, (ARAÚJO, 2006), posteriormente, no ano de 1969, Pritchard foi o primeiro a usar a terminologia atual (Medeiros: Vitoriano, 2015). As bases que sustentam a bibliometria são três leis: Lei de Bradford, Lei de Lotka e Lei de Zipf (GUEDES; BORSCHIVER, 2005). As características de cada uma delas são apresentadas no Quadro 1. 
Quadro 1 Leis da Bibliometria

Leis

Bradford

Leis de tífico e tecnológico e a região de concentração de termos Zipf de indexação, ou palavras-chave, que um pequeno grupo de palavras ocorre muitas vezes e um grande número de palavras é de pequena frequência de ocorrência.

Fonte: Adaptado de Guedes e Borschiver (2005, p. 3-4).

Como exemplos de uso destas leis Guedes e Borschiver (2005, p. 14) citam que a Lei de Bradford pode ser aplicada para "estimar o grau de relevância de periódicos, em dada área do conhecimento", com vistas a identificar autores ou periódicos que mais se destacam em um tema específico; a Lei de Lotka "para estimar o grau de relevância de autores, em dada área do conhecimento", cujo objetivo central consiste em identificar o impacto das publicações de um autor na sua área de pesquisas; e as Leis de Zipf podem ser aplicadas para "indexação automática de artigos científicos e tecnológicos", tendo por finalidade principal a estimação dos temas mais presentes nas pesquisas relacionadas a uma área específica do conhecimento.

$\mathrm{Na}$ área de ciências sociais aplicadas as pesquisas bibliométricas destinadas ao exame da produção científica, especialmente de artigos científi- 
cos, em alguma área específica do conhecimento, possibilita não só mapear e identificar os pesquisadores, bem como as suas motivações (CHUEKE; AMATUCCI, 2015). A bibliometria fornece, então, "um poderoso conjunto de métodos e medidas para estudar a estrutura e o processo de comunicação científica", visto contemplar diversos métodos e medidas que servem para avaliar a produção e para comparar e reconhecer os autores (BORGMAN; FURNER, 2002, p. 4).

Small (1973) desenvolveu uma forma de analisar o vínculo entre dois documentos, tendo por base o estudo da frequência com que estes são citados juntos e denominou esta técnica como análise de cocitação. Assim, dentre as informações das produções científicas que podem ser feitas na bibliometria está a análise das cocitações. Uma cocitação refere-se às ocorrências conjuntas em um documento, isto é, uma cocitação ocorre no momento em que dois documentos, autores ou periódicos estão presentes nas referências de uma publicação posterior (WHITE; GRIFFITH, 1981). Ressalta-se que a proximidade e a interlocução de dois documentos, quando se trata de análise de cocitação, não são determinadas pelos autores dos documentos, mas a comunidade científica que se apropria do conteúdo daqueles documentos estabelece conexões enquanto geram novos conhecimentos.

A análise da produção científica pode ser apresentada de modo descritivo ou por meio do uso indicadores, aplicando, entre outras, análises multivariadas dos dados bibliométricos, como, por exemplo, a Análise Fatorial Exploratória (VANZ; STUMPF, 2010). Os softwares são bons aliados quando se trata de análises bibliométricas, pois possibilitam a representação de grande volume de informações por intermédio de mapas e agrupamentos (MACHADO, 2015). A fonte de dados para a realização dos estudos bibliométricos refere-se principalmente às bases de dados, como, por exemplo, Scopus, Web Of Science e Periódicos Capes. 


\section{METODOLOGIA}

A seleção dos artigos foi realizada por meio de duas buscas em bases de dados, nos sítios eletrônicos Web of Knowledge e Scopus, com as palavras chave Entrepreneurial or Entrepreneurship e Propensity, conforme mencionado anteriormente. A busca na Web of Science resultou em 270 artigos e na Scopus em 367 artigos. Optou-se pela base do Scopus por apresentar maior quantidade de publicações. Ao todo, estas 367 publicações, contém 15.484 citações de outras publicações que incluem livros e artigos publicados em periódicos, sendo estas o objeto desta análise (Análise de Cocitação - AC).

A cocitação é a citação conjunta de dois artigos em uma literatura posterior (SMALL, 1973). A premissa da AC é que se dois ou mais documentos ou autores são citados juntos em uma pesquisa posterior, existe uma proximidade temática, conceitual ou metodológica entre os citados, na visão do autor citante (SMIRAGLIA, 2011). Assim, quanto maior o número de vezes que dois documentos ou autores são citados, concomitantemente, maior a probabilidade de que sejam relacionados em conteúdo (Bellardo, 1980), evidenciando a base do conhecimento em um campo científico. A proximidade e a interlocução de dois documentos não são determinadas pelos seus autores, mas pela comunidade científica que se apropria desse conteúdo e estabelece conexões a fim de gerar novos conhecimentos.

O Bibexcel foi utilizado na organização dos dados para a análise bibliométrica e o Statistical Package for the Social Sciences (SPSS) para realizar a AFE, a qual tem por objetivo analisar o padrão de correlações existentes entre as variáveis e utilizar esses padrões de correlações para agrupar suas variáveis em um número menor de dimensões (HAIR et al., 2009).

Quanto aos critérios para a seleção das publicações cocitadas a serem analisadas, enfatiza-se que não há na literatura vigente uma especificação de quantidade mínima ou máxima a ser adotada e, portanto, fica a critério do próprio pesquisador. No entanto, para realizar a Análise Fatorial Exploratória o primeiro indicador a ser observado é a medida de adequacidade da amostra de Kaiser-Meyer-Olkin (KMO), a qual deve ser superior a 0,60 (Hair et al., 2009), pois somente valores entre 0,6 e 1,0 indicam que a aná- 
lise fatorial é apropriada para aquele conjunto de dados. No processo de seleção das publicações cocitadas a serem analisadas, realizaram-se diversas tentativas inserindo dados de quarenta até cem publicações mais citadas, respeitando a ordem decrescente de quantidade de citações. Contudo, dada a diversidade de temas presentes nas publicações, o KMO geral de 0,60 só foi atingido quando foram selecionadas 41 publicações, nas quais a mais citada teve 113 ocorrências e a menos 27 ocorrências. No entanto, uma delas estava entre as mais citadas somente por ser de metodologia, não sendo pertinente para o presente estudo. Esta publicação foi excluída da amostra, restando quarenta publicações, usadas para a geração da matriz de cocitação e posterior análise fatorial exploratória no SPSS.

$\mathrm{Na}$ AFE, os dados agruparam-se em oito dimensões e seguiu-se os procedimentos recomendados por Hair et al. (2009) avaliando: KMO geral (acima de 0,6), teste de Esfericidade de Bartlett $(<0,05), \mathrm{KMO}$ de cada variável na matriz anti-imagem (acima de 0,5 ), em seguida, ajustando-se o modelo com a exclusão de variáveis com comunalidade abaixo de 0,5 , bem como das variáveis com cargas cruzadas (acima de 0,5 em mais de um fator); e, na matriz rotativa, analisou-se as cargas fatoriais, visando excluir aquelas que apresentassem carga negativa. O método de rotação ortogonal dos fatores foi o Varimax, um dos métodos mais utilizados, considerado por Hair et al. (2009) como superior a outros métodos de rotação fatorial ortogonal quando se pretende conseguir uma estrutura fatorial simplificada.

Cada publicação selecionada para a AFE foi tratada como sendo uma variável. Cabe destacar que somente uma variável era excluída por vez. Assim, a AFE foi executada diversas vezes para que as variáveis ficassem ajustadas. Após a exclusão das variáveis com KMO individual inferiores a 0,50, foi analisada a matriz rotativa gerada no SPSS, momento em que a variável Lumpkin_Dess_1996 foi excluída por apresentar carga negativa no fator. Restando, portanto, 24 variáveis que compõem a estrutura da produção científica na área de empreendedorismo. No resultado final da AFE, com 24 variáveis, o KMO geral foi de 0,625, a variância total explicada de $68,34 \%$ e o teste de Esfericidade de Bartlett de 0,000. 


\section{RESULTADOS}

O tema propensão ao empreendedorismo tem sido mais estudado nas últimas décadas e sua evolução ao longo do tempo pode ser visualizada na Figura 2, sendo possível observar que $61 \%$ das publicações ocorreram a partir do ano de 2010, demonstrando a atualidade do tema.

Figura 2 Evolução das publicações de 1970 a 2016

300

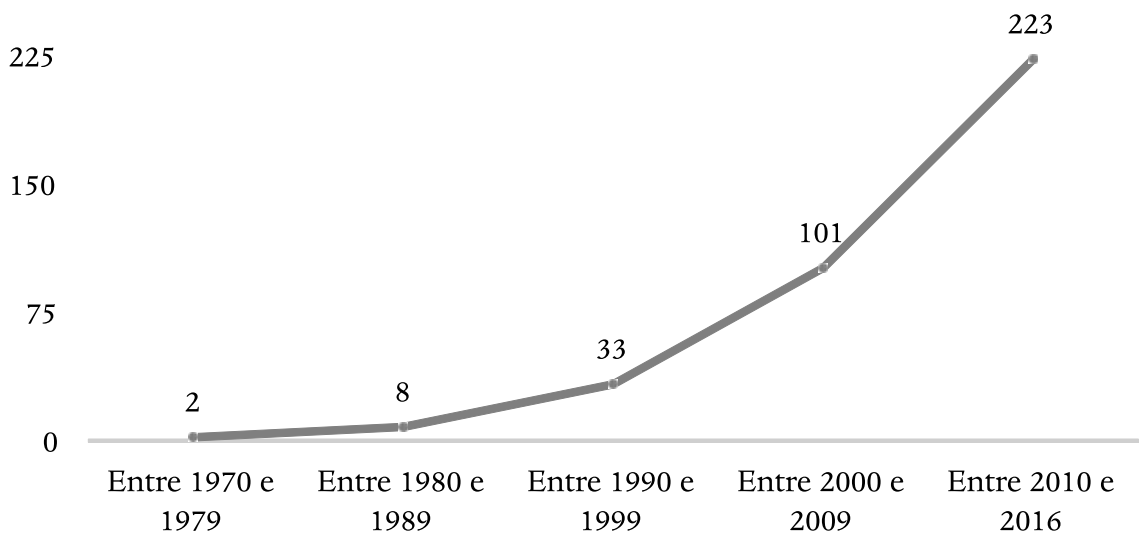

Fonte: Elaborado pelos autores

Para identificar a estrutura da produção científica referente à propensão ao empreendedorismo foram analisadas as cocitações que demonstram a relação entre dois artigos com base no número de publicações em que aparecem citados juntos tendo sido a obra The Achieving Society de McClelland (1961) a mais citada com 113 ocorrências. Na tabela 1, elencam-se as quarenta publicações mais citadas nos 367 artigos que permaneceram para a AFE, onde é possível observar que em 113 publicações $(30,79 \%)$ o artigo de McClelland (1961) é citado. 
Tabela 1 Artigos e livros mais citados nos artigos sobre propensão ao empreendedorismo

\begin{tabular}{|c|c|c|c|}
\hline Autor/ano & Título & Citações & $\%$ \\
\hline McClelland_1961 & The Achieving Society & 113 & $30,79 \%$ \\
\hline $\begin{array}{l}\text { Lumpkin_ } \\
\text { Dess_1996 }\end{array}$ & $\begin{array}{l}\text { Clarifying The Entrepreneur- } \\
\text { ial Orientation Construct and } \\
\text { Linking it to Performance }\end{array}$ & 77 & $20,98 \%$ \\
\hline Schumpeter_1934 & $\begin{array}{l}\text { The Theory of Economic De- } \\
\text { velopment }\end{array}$ & 76 & $20,71 \%$ \\
\hline $\begin{array}{l}\text { Reynolds_Bygra- } \\
\text { ve_Autio_2003 }\end{array}$ & $\begin{array}{l}\text { Global Entrepreneurship Moni- } \\
\text { tor: } 2003 \text { Global Report }\end{array}$ & 67 & $18,26 \%$ \\
\hline Ajzen_1991 & $\begin{array}{l}\text { The Theory of Planned Behav- } \\
\text { ior }\end{array}$ & 54 & $14,71 \%$ \\
\hline Knight_1921 & Risk, Uncertainty and Profit & 53 & $14,44 \%$ \\
\hline Gartner_1988 & $\begin{array}{l}\text { Who Is An Entrepreneur? Is } \\
\text { The Wrong Question }\end{array}$ & 51 & $13,90 \%$ \\
\hline $\begin{array}{l}\text { Shane_Venkatara- } \\
\text { man_2000 }\end{array}$ & $\begin{array}{l}\text { The Promise of Entrepreneur- } \\
\text { ship as a Field of Research }\end{array}$ & 51 & $13,90 \%$ \\
\hline $\begin{array}{l}\text { Shapero_ } \\
\text { Sokol_1982 }\end{array}$ & $\begin{array}{l}\text { Social Dimensions of Entrepre- } \\
\text { neurship }\end{array}$ & 51 & $13,90 \%$ \\
\hline Rotter_1966 & $\begin{array}{l}\text { Generalized Expectations for } \\
\text { Internal Versus External Con- } \\
\text { trol of Reinforcement }\end{array}$ & 46 & $12,53 \%$ \\
\hline Brockhaus_1980 & $\begin{array}{l}\text { Risk Taking Propensity of En- } \\
\text { trepreneurs }\end{array}$ & 44 & $11,99 \%$ \\
\hline Drucker_1985 & $\begin{array}{l}\text { Innovation and Entrepreneur- } \\
\text { ship }\end{array}$ & 43 & $11,72 \%$ \\
\hline Schumpeter_1936 & $\begin{array}{l}\text { The Theory of Economic De- } \\
\text { velopment: An Inquiry Into } \\
\text { Profits }\end{array}$ & 43 & $11,72 \%$ \\
\hline $\begin{array}{l}\text { Covin_Sle- } \\
\text { vin_1991 }\end{array}$ & $\begin{array}{l}\text { A Conceptual Model of Entre- } \\
\text { preneurship as Firm Behavior }\end{array}$ & 41 & $11,17 \%$ \\
\hline
\end{tabular}




\begin{tabular}{|c|c|c|c|}
\hline Penrose_1959 & $\begin{array}{l}\text { The Theory of Growth of The } \\
\text { Firm }\end{array}$ & 39 & $10,63 \%$ \\
\hline $\begin{array}{l}\text { Robinson_- } \\
\text { etal_1991 }\end{array}$ & $\begin{array}{l}\text { An Attitude Approach to the } \\
\text { Prediction of Entrepreneurship }\end{array}$ & 38 & $10,35 \%$ \\
\hline Shaver_Scott_1991 & $\begin{array}{l}\text { Person, Process, Choice: The } \\
\text { Psychology of New Venture } \\
\text { Creation }\end{array}$ & 37 & $10,08 \%$ \\
\hline Storey_1994 & $\begin{array}{l}\text { Understanding the Small Busi- } \\
\text { ness Sector }\end{array}$ & 37 & $10,08 \%$ \\
\hline Shane_2003 & $\begin{array}{l}\text { A General Theory of Entrepre- } \\
\text { neurship: the Individual-Op- } \\
\text { portunity Nexus }\end{array}$ & 36 & $9,81 \%$ \\
\hline $\begin{array}{l}\text { Krueger_Reilly_ } \\
\text { Carsrud_2000 }\end{array}$ & $\begin{array}{l}\text { Competing Models of Entre- } \\
\text { preneurial Intentions }\end{array}$ & 35 & $9,54 \%$ \\
\hline Brockhaus_1982 & $\begin{array}{l}\text { The Psychology of The Entre- } \\
\text { preneur }\end{array}$ & 34 & $9,26 \%$ \\
\hline Kirzner_1973 & $\begin{array}{l}\text { Competition and Entrepre- } \\
\text { neurship }\end{array}$ & 34 & $9,26 \%$ \\
\hline Koh_1996 & $\begin{array}{l}\text { Testing Hypotheses of Entre- } \\
\text { preneurial Characteristics: A } \\
\text { Study of Hong Kong MBA } \\
\text { Students }\end{array}$ & 34 & $9,26 \%$ \\
\hline $\begin{array}{l}\text { Covin_Sle- } \\
\text { vin_1989 }\end{array}$ & $\begin{array}{l}\text { Strategic Management of } \\
\text { Small Firms In Hostile and Be- } \\
\text { nign Environments }\end{array}$ & 33 & $8,99 \%$ \\
\hline $\begin{array}{l}\text { Busenitz_ } \\
\text { Barney_1997 }\end{array}$ & $\begin{array}{l}\text { Differences Between Entrepre- } \\
\text { neurs and Managers in Large } \\
\text { Organizations: Biases and } \\
\text { Heuristics in Strategic Deci- } \\
\text { sion-Making }\end{array}$ & 32 & $8,72 \%$ \\
\hline
\end{tabular}




\begin{tabular}{|c|c|c|c|}
\hline $\begin{array}{l}\text { Davidsson_Ho- } \\
\text { nig-2003 }\end{array}$ & $\begin{array}{l}\text { The Role of Social and Human } \\
\text { Capital Among Nascent Entre- } \\
\text { preneurs }\end{array}$ & 32 & $8,72 \%$ \\
\hline $\begin{array}{l}\text { Evans_Leigh- } \\
\text { ton_1989 }\end{array}$ & $\begin{array}{l}\text { Some Empirical Aspects of En- } \\
\text { trepreneurship }\end{array}$ & 32 & $8,72 \%$ \\
\hline $\begin{array}{l}\text { Mueller_Tho- } \\
\text { mas_2001 }\end{array}$ & $\begin{array}{l}\text { Culture and Entrepreneurial } \\
\text { Potential: A Nine Country } \\
\text { Study of Locus of Control and } \\
\text { Innovativeness }\end{array}$ & 32 & $8,72 \%$ \\
\hline Sitkin_Pablo_1992 & $\begin{array}{l}\text { Reconceptualizing the Deter- } \\
\text { minants of Risk Behavior }\end{array}$ & 31 & $8,45 \%$ \\
\hline $\begin{array}{l}\text { Stewart_ } \\
\text { Roth_2001 }\end{array}$ & $\begin{array}{l}\text { Risk Propensity Differences } \\
\text { Between Entrepreneurs and } \\
\text { Managers: A Meta-Analytic } \\
\text { Review }\end{array}$ & 31 & $8,45 \%$ \\
\hline Krueger_1993 & $\begin{array}{l}\text { The Impact of Prior Entrepre- } \\
\text { neurial Exposure on Percep- } \\
\text { tions of New Venture Feasibili- } \\
\text { ty and Desirability }\end{array}$ & 30 & $8,17 \%$ \\
\hline $\begin{array}{l}\text { Simon_Hough- } \\
\text { ton_Aquino_1999 }\end{array}$ & $\begin{array}{l}\text { Cognitive Biases, Risk Percep- } \\
\text { tion, and Venture Formation: } \\
\text { How Individuals Decide To } \\
\text { Start Companies }\end{array}$ & 30 & $8,17 \%$ \\
\hline $\begin{array}{l}\text { Hornaday_ } \\
\text { Aboud_1971 }\end{array}$ & $\begin{array}{l}\text { Characteristics of Successful } \\
\text { Entrepreneurs }\end{array}$ & 29 & $7,90 \%$ \\
\hline Kirzner_1979 & $\begin{array}{l}\text { Perception, Opportunity and } \\
\text { The Profit: Studies in the Theo- } \\
\text { ry of Entrepreneurship }\end{array}$ & 29 & $7,90 \%$ \\
\hline Timmons_1994 & New Venture Creation & 29 & $7,90 \%$ \\
\hline Hamilton_2000 & $\begin{array}{l}\text { Does Entrepreneurship Pay? } \\
\text { An Empirical Analysis of the } \\
\text { Returns to Self-Employment }\end{array}$ & 28 & $7,63 \%$ \\
\hline
\end{tabular}




\begin{tabular}{|c|c|c|c|}
\hline Bird_1988 & $\begin{array}{l}\text { Implementing Entrepreneurial } \\
\text { Ideas: The Case for Intention }\end{array}$ & 27 & $7,36 \%$ \\
\hline $\begin{array}{l}\text { Low_Mac- } \\
\text { millan_1988 }\end{array}$ & $\begin{array}{l}\text { Entrepreneurship: Past Re- } \\
\text { search and Future Challenges }\end{array}$ & 27 & $7 \%$ \\
\hline Miller_1983 & $\begin{array}{l}\text { The Correlates of Entrepre- } \\
\text { neurship in Three Types of } \\
\text { Firms }\end{array}$ & 27 & $7,36 \%$ \\
\hline $\begin{array}{l}\text { Evans_Jovano- } \\
\text { vic_1989 }\end{array}$ & $\begin{array}{l}\text { An Estimated Model of En- } \\
\text { trepreneurial Choice Under } \\
\text { Liquidity Constraints }\end{array}$ & 27 & $7,36 \%$ \\
\hline
\end{tabular}

Fonte: Elaborada pelos autores

A matriz das quarenta publicações mais citadas foi utilizada para a execução da análise fatorial exploratória. A partir da AFE tornou-se possível avaliar os padrões existentes entre as publicações citadas pelos 367 artigos sobre a propensão ao empreendedorismo. No SPSS, cada publicação foi tratada como uma variável. Nessa análise, o primeiro teste executado foi o de Kayser-Meyer Olkin (KMO), que varia entre 0 e 1 e indica se a amostra pode ser tratada pelo método de análise fatorial (WILLIAMS; ONSMAN; BROWN, 2010). Para ajustar o modelo, o valor do teste KMO de cada variável foi analisado. O valor mínimo indicado para do teste $\mathrm{KMO}$ para cada variável deveria ser 0,5 . Assim, se o valor do KMO individual de uma variável era menor que 0,5 , a variável era excluída e a análise fatorial executada novamente. Após o ajuste do KMO individual, analisou-se a comunalidade de cada variável, sendo que todas ficaram superiores a 0,50 , se o valor da comunalidade for próximo de zero, isto indica que a variável tem baixa correlação com o fator (FÁVERO et al., 2009). Das quarenta variáveis selecionadas para a realização da AFE, quinze foram excluídas por apresentarem KMO individual inferior a 0,50, conforme demonstrado na tabela 2 . 
Tabela 2 Variáveis excluídas por apresentarem KMO individual inferior a 0,50

\begin{tabular}{lccc}
\multicolumn{1}{c}{ Autor } & $\begin{array}{c}\text { KMO } \\
\text { individual }\end{array}$ & $\begin{array}{c}\text { KMO geral } \\
\text { após a exclu- } \\
\text { são do autor }\end{array}$ & $\begin{array}{c}\text { Variância total } \\
\text { explicada após } \\
\text { a exclusão do } \\
\text { autor }\end{array}$ \\
\hline Brockhaus_1982 & 0,01 & 0,594 & $46,91 \%$ \\
Kirzner_1979 & 0,01 & 0,595 & $48,12 \%$ \\
\hline Mcclelland_1961 & 0,018 & 0,596 & $49,39 \%$ \\
\hline Storey_1994 & 0,019 & 0,598 & $50,73 \%$ \\
\hline Knight_1921 & 0,021 & 0,599 & $52,14 \%$ \\
\hline Evans_Leighton_1989 & 0,039 & 0,599 & $53,61 \%$ \\
\hline Evans_Jovanovic_1989 & 0,048 & 0,599 & $55,14 \%$ \\
\hline Sitkin_Pablo_1992 & 0,282 & 0,601 & $56,39 \%$ \\
\hline Timmons_1994 & 0,278 & 0,628 & $58,01 \%$ \\
\hline Low_Macmillan_1988 & 0,334 & 0,622 & $59,24 \%$ \\
\hline Reynolds_Bygrave_Au- & 0,21 & 0,64 & $60,93 \%$ \\
tio_2003 & 0,344 & 0,632 & $63,32 \%$ \\
\hline Davidsson_Honig_2003 & 0,38 & 0,643 & $63,82 \%$ \\
\hline Ajzen_1991 & 0,387 & 0,634 & $65,14 \%$ \\
\hline Shane_Venkatara- & 0,401 & 0,634 & $66,90 \%$ \\
\hline man_2000 & & & \\
\hline Schumpeter_1934 & $0,54 \%$ & \\
\hline
\end{tabular}

Fonte: Elaborada pelos autores

Após a exclusão das variáveis com KMO inferiores a 0,50, foi analisada a matriz rotativa gerada no SPSS e a variável Lumpkin_Dess_1996 foi excluída por apresentar carga negativa no fator, posterior a sua exclusão as cumunalidades das demais variáveis ficaram superiores a 0,50. Restando, portanto, 24 variáveis que compõem a estrutura intelectual da produção científica na área de empreendedorismo. Convém salientar que somente 
uma variável foi excluída por vez. Assim, a AFE foi executada diversas vezes para que o modelo ficasse ajustado.

O resultado final da AFE gerou um KMO geral de 0,625, a variância total explicada com oito dimensões foi de $68,34 \%$ e o teste de Esfericidade de Bartlett manteve-se em 0,000, demonstrando que há correlação entre as variáveis. As análises evidenciaram que a estrutura da produção científica sobre propensão ao empreendedorismo é explicada em $68,34 \%$ por 24 autores, exibindo o grau de associação entre pares de documentos, de acordo com a compreensão da comunidade de autores citantes, ou seja, conforme são reconhecidos pelos citantes (SMALL, 1973). Após a execução da análise fatorial exploratória, os artigos foram agrupados em fatores (dimensões), conforme ilustra a tabela 3 . 
Tabela 3 Análise Fatorial Exploratória das cocitações

\begin{tabular}{|c|c|c|c|c|c|c|c|c|}
\hline Variável (autor) & 1 & 2 & 3 & 4 & 5 & 6 & 7 & 8 \\
\hline Covin_Slevin_1989 & ,824 & & & & & & & \\
\hline Miller_1983 & ,758 & & & & & & & \\
\hline Covin_Slevin_1991 & ,705 & & & & & & & \\
\hline Gartner_1988 & ,660 & & & & & & & \\
\hline Kirzner_1973 & & ,894 & & & & & & \\
\hline Hornaday_Aboud_1971 & & ,829 & & & & & & \\
\hline Brockhaus_1980 & & 707 & & & & & & \\
\hline Koh_1996 & & ,540 & & & & & & \\
\hline Robinson_etal_1991 & & & 859 & & & & & \\
\hline Drucker_1985 & & & ,831 & & & & & \\
\hline Shaver_Scott_1991 & & &, 715 & & & & & \\
\hline Krueger_1993 & & & & ,912 & & & & \\
\hline Bird_1988 & & & & ,825 & & & & \\
\hline Krueger_Reilly_ & & & & 7 & & & & \\
\hline Carsrud_2000 & & & & & & & & \\
\hline Mueller_Thomas_2001 & & & & & ,787 & & & \\
\hline Hamilton_2000 & & & & & ,737 & & & \\
\hline Rotter_1966 & & & & & ,582 & & & \\
\hline Stewart_Roth_2001 & & & & & ,569 & & & \\
\hline Simon_Houghton_ & & & & & & & & \\
\hline Aquino_1999 & & & & & & ,858 & & \\
\hline Penrose_1959 & & & & & & ,665 & & \\
\hline Shane_2003 & & & & & &, 503 & & \\
\hline Schumpeter_1936 & & & & & & & 836 & \\
\hline Shapero_Sokol_1982 & & & & & & & 836 & \\
\hline Busenitz_Barney_1997 & & & & & & & & ,918 \\
\hline
\end{tabular}

Fonte: Elaborada pelos autores

A partir deste agrupamento, os resumos de cada publicação foram analisados qualitativamente a fim de identificar os padrões apresentados pelas publicações e, em seguida, foram atribuídos nomes para cada dimensão, conforme se apresenta a seguir. 


\section{ESTRUTURA INTELECTUAL DA PRODUÇÃO CIENTÍFICA}

\section{DIMENSÃO 1 - EMPREENDEDORISMO COMO PROCESSO ORGANIZACIO- NAL}

Esta dimensão relaciona os processos organizacionais com o empreendedorismo. Apresenta, em seu conteúdo, os fatores contextuais, os aspectos relacionados ao ambiente e a estrutura organizacional, além de abordar a tomada de decisões como um dos elementos do processo inerentes da empresa. Covin e Slevin (1989) relatam os resultados de um estudo destinado a investigar as respostas estratégicas eficazes em face da hostilidade ambiental entre as pequenas empresas industriais. Nesse estudo foram analisados a estrutura organizacional, postura estratégica, táticas competitivas e desempenho financeiro. Observaram ainda que o desempenho das pequenas empresas em ambientes hostis está positivamente relacionado a uma estrutura orgânica, uma postura estratégica empresarial e um perfil competitivo caracterizado por uma orientação de longo prazo, altos preços dos produtos e uma preocupação em prever as tendências da indústria. Por outro lado, em ambientes benignos, o desempenho foi positivamente relacionado a uma estrutura mecanicista, uma postura estratégica conservadora e um perfil competitivo caracterizado por uma gestão financeira conservadora e uma orientação financeira de curto prazo.

Miller (1983) buscou em sua pesquisa descobrir os principais determinantes do empreendedorismo. Essa pesquisa explica que alguns autores argumentaram que a personalidade do líder determina o empreendedorismo, destacam o papel desempenhado pela estrutura da organização, enquanto outros têm indicam a importância da tomada de decisão estratégica. Diante disso, Miller (1983) considera que a extensão empresarial é influenciada por todos estes fatores que, em grande parte, dependem da natureza da organização. Tendo como base os estudos de um número de autores, fez uma derivação das empresas em dois tipos: empresas simples (são pequenas e seu poder é centralizado na parte superior) e empresas orgânicas (se esforçam para serem adaptáveis ao seu ambiente, enfatizando a gestão baseada em experiência e comunicações abertas). Constatou que, nas empresas sim- 
ples, o empreendedorismo é determinado pelas características do líder e o planejamento destas empresas é facilitado por estratégias de produto-mercado explícitas e bem integradas, enquanto que nas empresas orgânicas o empreendedorismo é uma função do ambiente e da estrutura.

Covin e Slevin (1991) desenvolveram um modelo conceitual de comportamento empresarial em nível organizacional. Esses autores assumem que o empreendedorismo é uma dimensão de postura estratégica, assim, todo tipo de organização pode se comportar de forma empreendedora. Quanto à postura estratégica, acreditam que engloba a propensão de assumir riscos, apresentar capacidade de ser competitivamente agressiva, desenvolver maneiras proativas, além de proporem inovação de produto. Do modelo que desenvolveram são derivadas quarenta e quatro proposições. Concluem que as empresas devem ser vistas como entidades empreendedoras e este comportamento empresarial é, muitas vezes, parte integrante da gestão da empresa.

Gartner (1988) ressalta que mesmo com inúmeras tentativas dos pesquisadores em definir o empreendedor, tendo como foco especialmente a abordagem de traços, ainda não existe nenhuma definição comum, pois as características mencionadas pelos estudiosos de empreendedorismo não são suficientes para diferenciar quem é e quem não é empreendedor. $\mathrm{O}$ autor oferece como alternativa para este impasse: uma abordagem comportamental, sugerindo que, uma vez que o empreendedorismo é a criação de organizações, a pesquisa deve se concentrar no que o empreendedor faz e não em quem é o empreendedor. Em seu estudo, as duas abordagens são apresentadas e contrastadas: a abordagem de traços assume que o empreendedor é um tipo de personalidade particular, um estado fixo de ser (uma vez um empreendedor, sempre um empreendedor) e a abordagem comportamental centra-se na organização e vê o indivíduo em termos de atividades (comportamento) ou de um papel desempenhado para permitir o funcionamento da organização. 


\section{DIMENSÃO 2 - CARACTERÍSTICAS DO EMPREENDEDOR}

Essa dimensão relaciona as características do empreendedor apresentando em seu conteúdo a capacidade de identificar e explorar oportunidades, histórico familiar, independência, poder, inovação, riscos associados à atuação empreendedora e outras características psicológicas que diferenciam empreendedores de não empreendedores. Kirzner (1973) no livro Competition and Entrepreneurship procurou estabelecer uma teoria do mercado e do sistema de preços com abordagem diferente da teoria dos preços vigentes na época, trazendo uma abordagem mais contemporânea. O autor via na teoria dos preços tradicional a explicação da configuração de preços e quantidades que satisfazem as condições de equilíbrio. Nesse viés, considera que tanto a concorrência quanto o empreendedorismo se preocupam com o funcionamento da economia de mercado e que a redescoberta do empreendedor deve emergir como um passo de grande relevância. Quanto à definição, Kirzner (1973) classifica o empreendedor como alguém que cria um equilíbrio em um ambiente de turbulência, identificando oportunidades. Ao tratar da obra de Kirzner (1973), Shane (2003) explica que a oportunidade decorre do equilíbrio e não requer novas informações, sendo comum e menos inovativa, com pouca abrangência quanto a novas descobertas.

Hornaday e Aboud (1971) realizaram uma pesquisa com a finalidade de desenvolver testes objetivos que fossem válidos e com formato que facilitasse tanto a aplicação quanto a interpretação. Em quatro estudos tentaram verificar se uma série de características pessoais diferenciam empreendedores de homens em geral e se essa pode ser medida por testes objetivos e padronizados (por exemplo: os empreendedores têm pontuações maiores na Edwards' Personal Preference Scale - EPPS que mede a necessidade de realização, necessidade de autonomia e necessidade de agressão). O estudo revela ainda que devido à natureza da pontuação da escala Occupational Interest Survey - OIS, as pontuações dos empreendedores não poderia ser comparadas com as das demais pessoas, pois teriam características que os diferenciava das pessoas em geral. Concluíram que as características do empreendedor compreendem necessidade de realização, autonomia, histórico 
familiar, agressividade, poder, reconhecimento de oportunidade, inovação e independência.

Brockhaus (1980) realizou um estudo para examinar se havia diferenças na propensão ao risco entre gerentes recém-contratados ou promovidos e fundadores de novos empreendimentos nos Estados Unidos. Os dados revelaram que, diferentemente de outros estudos que validavam de forma positiva a associação do risco à atividade empreendedora, a propensão ao risco não distingue, de maneira significativa, empreendedores e não empreendedores, ou seja, a propensão para a "tomada de risco" não é diferente entre empreendedores, gestores e população em geral. Em sua investigação, baseada nas características empreendedoras, Brockhaus (1980) considera que as pessoas não nascem empreendedoras, mas podem vir a ser.

Koh (1996) argumenta que existe pouco consenso na definição de empreendedorismo e o que faz um empreendedor. Com a intenção de ampliar as discussões sobre as características preditoras da inclinação para o empreendedorismo, realizou um estudo para testar hipóteses de características empreendedoras. Nesse estudo adota as características psicológicas da escola de empreendedorismo, que vê empreendedores como indivíduos com valores, atitudes e necessidades únicas que os conduzem e os diferenciam de não empreendedores. Investiga se a inclinação empreendedora é significativamente associada às seguintes características psicológicas: necessidade de realização, locus de controle, propensão a assumir riscos, tolerância à ambiguidade, autoconfiança e inovação. Os resultados indicaram que os indivíduos inclinados para o empreendedorismo têm uma maior propensão para assumir riscos, mais tolerância à ambiguidade e maior inovação em comparação com aqueles sem inclinação para o empreendedorismo. Assim, as estatísticas descritivas sugerem que aqueles com maior inclinação para o empreendedorismo também possuem maior necessidade de realização, maior locus de controle (interno) e mais autoconfiança, ou seja, as seis características psicológicas testadas foram confirmadas como sendo preditoras da inclinação para o empreendedorismo. 


\section{DIMENSÃO 3 - ATITUDE E COMPORTAMENTO EMPREENDEDOR}

As atitudes e os comportamentos empreendedores agrupam a dimensão 3 por considerarem os traços de personalidade e as características demográficas dos empreendedores, abordando tanto os aspectos afetivos como os cognitivos, como alguns dos requisitos para o enfrentamento dos desafios em face dos negócios. Robinson et al. (1991) acreditam que a atitude, em comparação com características pessoais (traços de personalidade) e características demográficas, é uma abordagem mais útil para descrever empreendedores. A escala Entrepreneurial Attitude Orientation Scale (EOA), desenvolvida e validada por estes autores, tem como objetivo mensurar a orientação para a atitude empreendedora e se baseia na mensuração das seguintes características fortemente associadas ao comportamento empreendedor: inovação, lócus de controle, autoestima e realização. Na escala EOA, o conceito de atitude é composto por três dimensões: afetiva, cognitiva e comportamental (ROBINSON et al., 1991). A atitude empreendedora é entendida como a predisposição cognitiva, afetiva ou comportamental para atuar de forma inovadora, com autocontrole, autoestima e necessidade de realização. De forma geral, este instrumento busca diferenciar empreendedores de não empreendedores.

Drucker (1985) no livro Innovation and Entrepreneurship, considerado como um clássico no campo da inovação e do empreendedorismo apresenta a inovação e o empreendedorismo como uma disciplina proposital e sistemática que explica e analisa os desafios e oportunidades da nova economia empresarial dos Estados Unidos. Quanto ao empreendedorismo, este autor, centra-se nas oportunidades, pois considera que o empreendedor está buscando constantemente a mudança, reagindo e explorando-a como uma oportunidade. Em relação à inovação, uma vez que cria algo novo, diferente, modifica ou transforma valores, não limita suas ações às instituições exclusivamente econômicas, mas consegue conviver com os riscos e incertezas presentes nas decisões que irá tomar. Qualquer pessoa pode aprender e se comportar de forma empreendedora (DRUCKER, 1985).

Segundo Shaver e Scott (1991), as pesquisas enfatizando fatores relacionados com a personalidade e as características demográficas têm como 
deficiência a tendência de negligenciarem a natureza intencional da atividade empreendedora. Para os autores, o comportamento é influenciado não apenas pela forma como o mundo exterior é representado na mente, assim como pelo exercício de escolha do indivíduo. Nessa pesquisa examinam a possibilidade de que os atributos permanentes de um indivíduo possam afetar a atividade empreendedora, descrevem os processos cognitivos propostos na construção de representações do ambiente externo e elencam variáveis motivacionais que influenciam as escolhas comportamentais. A identificação do potencial empreendedor requer uma infraestrutura cognitiva apropriada (SHAVER; SCOTT, 1991).

\section{DIMENSÃO 4 - ANTECEDENTES DA INTENÇÃO EMPREENDEDORA}

A dimensão 4 integra os antecedentes da intenção empreendedora, propiciando evidências dos fatores internos e externos que propulsionam os indivíduos a vislumbrarem a atuação no empreendedorismo como uma opção de carreira. Aborda também a importância do planejamento, pois o empreendedorismo é tido como sendo um comportamento planejado, sendo as intenções um preditor da ação de empreender. Krueger (1993) testou o impacto da exposição prévia ao empreendedorismo usando como base a Teoria da Intenção Empreendedora, cujos precursores foram Shapero e Sokol (1982), os quais consideram que duas etapas interativas são fundamentais: a desejo e a viabilidade. Assim, se um indivíduo acredita na viabilidade para iniciar um novo negócio, o desejo cresce na mesma proporção, entretanto, se ele não estiver motivado para iniciar um novo negócio, sequer considerará a sua viabilidade. Krueger (1993) pressupõe que a intenção de iniciar um novo negócio tem como antecedentes o desejo nessa realização, a viabilidade e a propensão do indivíduo a agir em função das oportunidades. A intenção empreendedora é o compromisso de iniciar um novo negócio, ou seja, uma predisposição de um indivíduo para criá-lo.

Bird (1988) afirma que a intenção de colocar em prática um determinado comportamento pode ser influenciada por vários fatores, tais como: necessidades, valores, desejos, hábitos e crenças. Sem intenção, a ação é improvável, por isso, ressalta que o estudo das intenções empreendedoras 
fornece suporte para a pesquisa sobre empreendedorismo, uma vez que são fundamentais para o entendimento de todo o processo empreendedor. A intenção pode ser vista como um estado de espírito que direciona a atenção da pessoa, a experiência e a ação para uma determinada situação, com o objetivo de fundar um novo negócio (Bird, 1988). O autor salienta que a intenção de empreender sofre influência de fatores internos e externos que propulsionam o indivíduo a vislumbrar um campo de atuação existente ou criar um ambiente novo possibilitando o desenvolvimento de suas motivações e capacidades empreendedoras.

Krueger, Reilly e Carsrud (2000) esclarecem que novos negócios surgem ao longo do tempo e envolve planejamento. Assim, o empreendedorismo é o tipo de comportamento planejado para o qual os modelos de intenção são ideais. Nesse estudo, os autores compararam dois modelos baseados em intenção empreendedora em termos de sua capacidade de prever as intenções empresariais: a Teoria do Comportamento Planejado de Ajzen (as intenções em geral dependem da percepção de atratividade pessoal, normas sociais e de viabilidade) e o modelo do Evento Empresarial de Shapero (as intenções empresariais dependem de percepções de conveniência pessoal, viabilidade e propensão para agir). Krueger, Reilly e Carsrud (2000) tratam o empreendedorismo como uma maneira de pensar que enfatiza oportunidades e ameaças identificadas pelo indivíduo que tem a intenção de empreender. Estes autores consideram o processo de identificação de oportunidade como sendo claramente intencional, oferecendo, por tanto, um meio para explicar e prever o empreendedorismo.

DIMENSÃO 5 - LÓCUS DE CONTROLE, ASSUNÇÃO DE RISCOS E EFEITOS DA CULTURA NO EMPREENDEDORISMO

Esta dimensão foi nominada Lócus de controle, assunção de riscos e efeitos da cultura no empreendedorismo. Essas duas primeiras características individuais são inerentes ao empreendedorismo e a cultura é o aspecto influenciador do processo empreendedor, atribuindo valores que conduzem e orientam as escolhas e os comportamentos. Por sua vez, Mueller e Thomas (2001, p. 62) analisaram os efeitos da cultura no empreendedorismo 
e os resultados apoiaram a proposição de que algumas culturas são mais propícias para o empreendedorismo do que outras.

Indivíduos com locus de controle interno e orientação inovadora deveriam aparecer mais frequentemente em culturas altamente individualistas com elementos de comportamento empreendedor fortemente independente e perseverante e ao mesmo tempo mantendo criatividade e inovatividade na resolução de problemas para lidar com um mundo incerto e ambíguo (MUELLER; THOMAS, 2000, p. 62).

A cultura pode condicionar o potencial para o empreendedorismo gerando diferenças entre as fronteiras nacionais e regionais, pois dependendo do momento permite a atribuição de significados e valores que conduzem e orientam escolhas e comportamentos das pessoas (MUELLER; THOMAS, 2001). Hamilton (2000) questiona a importância dos retornos monetários quando se pensa em abrir um novo negócio. Destaca que, em um quadro teórico microeconômico, os empreendedores não buscam maximizar seus rendimentos monetários, mas sim a sua utilidade geral, que pode ser expressa de diversas formas, pois os resultados de seu estudo sugerem que os benefícios não pecuniários do emprego por conta própria são mais substantivos. $\mathrm{O}$ autor constatou que, na média, a atividade empreendedora não fornece os melhores resultados em termos de rendimentos monetários para os indivíduos, mas os empreendedores engajam-se em atividades com retornos não pecuniários (por exemplo: status social, o controle sobre a sua própria rotina e a satisfação pessoal em ter o próprio negócio) relevantes e permanece na mesma ocupação, apesar de ter alternativas ocupacionais que trariam maiores retornos tanto no início quanto no longo prazo.

Rotter (1966) foi um dos precursores no estudo do locus de controle no campo da Teoria da Aprendizagem Social e desenvolveu a IE Scale (escala de locus de controle interno-externo) para mensurar a internalidade ou a externalidade de locus de controle. O locus de controle refere-se a uma característica psicológica que demonstra o grau em que o indivíduo percebe que o que acontece na sua vida, no dia a dia como consequência das suas ações e, por ser consequência, pode controlar estes acontecimentos 
(controle interno) ou, como não tendo relação com o seu comportamento e, por isso, estão fora do seu controle (controle externo). Não obstante, Coleta (1979) explica que o constructo de locus de controle refere-se à percepção das pessoas a respeito da fonte de controle, se própria do sujeito (interna) ou pertencente a algum elemento fora de si próprio (externa), sendo importante tanto na predição quanto no controle e modificação do comportamento humano, Rotter (1966) complementa que lócus de controle refere-se às crenças dos indivíduos sobre o que controla seu próprio comportamento. Esse construto é tratado como um contínuo, sendo que, em um extremo, a pessoa compreenderia que o controle depende de seus esforços e capacidades; e, no outro extremo, o controle é percebido como dependente de aspecto fora de seu controle como outras pessoas ou entidades e do acaso, destino ou sorte.

Stewart e Roth (2001) estudaram a propensão dos indivíduos a assumirem riscos e consideram que tem uma interconexão com a exploração das oportunidades, uma vez que assumir riscos faz parte fundamental da atividade empresarial. A conclusão da meta-análise é de que os empreendedores têm uma propensão ao risco mais elevada do que os gestores, a qual é particularmente pronunciada entre aqueles que são orientados para o crescimento. Estes autores veem a assunção de riscos como uma variável-chave para a teorização futura sobre o processo de empreendedorismo. Posteriormente, Miner e Raju (2004) realizaram outra meta-análise acerca do mesmo tema, adicionando quatorze artigos que não foram incluídos na análise anterior e refutaram os resultados de Stewart e Roth (2001), concluindo que deve ser mantida uma visão conservadora, com a posição de que o papel da propensão ao risco no empreendedorismo permanece não resolvido.

\section{DIMENSÃO 6 - PROCESSOS COGNITIVOS E IDENTIFICAÇÃO DE OPORTU- NIDADES}

Os processos cognitivos e a identificação de oportunidades são dois aspectos recorrentes na literatura do empreendedorismo. Os processos cognitivos se mostram como facilitadores das ações empreendedoras podendo 
desencadear a capacidade de identificar oportunidade para empreender. Simon, Houghton e Aquino (2000) estudaram os processos cognitivos seguidos pelos empreendedores, isto é, como os indivíduos lidam com os riscos inerentes às suas decisões. Nessa pesquisa investigaram os três vieses cognitivos para fazer julgamentos, que, em pesquisas anteriores, havia sido sugerido que poderiam diminuir a percepção de risco: a) o excesso de confiança (a falta de conhecimento dos limites do próprio conhecimento); b) a ilusão de controle (os indivíduos acreditam que podem controlar eventos em grande parte incontroláveis e que podem prever com precisão o resultado dos eventos); e c) a crença na lei de números pequenos (quando um indivíduo usa um número limitado de insumos informativos - uma pequena amostra de informações) para tirar conclusões decisivas. Os resultados do estudo sugerem que os indivíduos iniciam empreendimentos por não perceberem os riscos envolvidos e não por aceitarem conscientemente os altos níveis de riscos (SIMON; HOUGHTON; AQUINO, 2000). Além disso, a crença na lei de números pequenos reduziu as percepções de um indivíduo sobre o risco de uma empresa, sugerindo que alguns indivíduos tiram grandes conclusões a partir de um conjunto pequeno de informações; uma ilusão de controle também diminui a percepção de risco, levando a crer que os empreendedores iniciantes podem não reconhecer que certas tarefas, importantes para o sucesso do empreendimento, encontram-se além de seu controle.

Penrose (1959) no livro The Theory of Growth of the Firm, considerado um dos trabalhos pioneiros na área de empreendedorismo, busca respostas para questões como: Por que algumas empresas obtêm melhores resultados do que outras? O que permite que uma empresa cresça e aproveite suas oportunidades? A autora analisa atividades gerenciais e decisões, rotinas organizacionais e criação de conhecimento dentro da empresa e argumenta que são críticas para a capacidade de uma empresa crescer. Em sua pesquisa, concluiu que a teoria da firma existente naquela época era insuficiente para explicar o porquê e como as firmas crescem. A firma é definida como uma "coleção de recursos produtivos cuja disposição entre diferentes usos e ao longo do tempo é determinada por razões administrativas" (PENRO- 
SE, 1959, p.24). Quanto ao empreendedorismo, o livro busca compreender as funções gerenciais e empreendedoras na habilidade da empresa no uso de seus recursos e considera algumas características que o empreendedor precisa ter para o sucesso do seu empreendimento, a saber: versatilidade (relacionada com a capacidade de imaginação e visão pessoal), ambição e capacidade de julgamento.

Shane (2003) no livro A General Theory of Entrepreneurship: The Individual-Opportunity Nexus toma por base uma variedade de literatura sobre empreendedorismo e desenvolve uma teoria mais abrangente para este campo, desde a descoberta de atividades empreendedoras até as diferenças da atividade empresarial na indústria para o processo organizacional. Ao ampliar a análise do empreendedorismo, o autor oferece uma estrutura conceitual abrangente capaz de explicar as diferentes partes do processo empreendedor: oportunidades, pessoas que as perseguem, habilidades e estratégias usadas tanto para organizar quanto para explorar as oportunidades e as condições ambientais favoráveis a estas de forma coerente. Além disso, considera que o empreendedorismo não deveria ser associado, exclusivamente, à abertura de novas empresas, mas à exploração de oportunidades de forma inovadora e à proposição de novas combinações meio-fim, cujo valor comercial dependeria do uso de mecanismos de mercado, como, por exemplo, patentes ou licenças.

\section{DIMENSÃO 7 - AÇÃO EMPREENDEDORA}

A dimensão 7, nominada ação empreendedora, contempla questões relacionadas à importância da inovação e à necessidade de realização como propulsoras do desenvolvimento econômico, propiciando o desenvolvimento de modelos de mensuração da intenção empreendedora. Schumpeter (1936) no livro The Theory of Economic Development: An Inquiry into Profits, considerado um clássico na análise da sociedade capitalista, enfatiza como dimensões fundamentais da ação empreendedora a resistência e o conflito institucional. Martes destaca quatro pontos fundamentais referentes às relações entre ação empreendedora e economia presentes na obra de Schumpeter (1936). Primeiro, 
Quanto à metodologia, define o indivíduo (empreendedor) como unidade básica de análise, mas o empresário é também concebido como um tipo ideal e ente portador de interesses, vontade e intencionalidade (MARTES, 2010, p. 255).

Segundo, quanto à inovação, é considerada como "elemento dinâmico da economia, consequentemente, o papel do empreendedor é fundamental na promoção do desenvolvimento econômico". Terceiro, quanto ao empresário inovador "é um tipo específico de agente, diferente do mero capitalista, pois ele decide racionalmente com base em valores (inovação), mas que também é guiado pela paixão (desejos e conquistas) e é, necessariamente, um líder". E, quarto ponto, referente ao aspecto institucional, o qual é considerado "fundamental: seja pelo apoio, seja pela oposição." Neste último ponto, Martes (2010, p. 255) explica que as instituições de crédito, as instituições políticas e econômicas, oferecem a base de sustentação à ação empreendedora e ajudam a alavancar um novo ciclo de crescimento, no entanto, é justamente das instituições que advém um forte movimento de oposição à ação empreendedora.

Shapero e Sokol (1982) estudaram a dimensão social do empreendedorismo e desenvolveram um modelo para mensurar a intenção empreendedora, denominado Entrepreneurial Event (SEE). O evento empreendedor (nascimento de um empreendedor) compreende a unidade de interesse especialmente em razão dos problemas referentes à definição do que seja um empreendedor em comparação com outros indivíduos. Os aludidos autores sugeriram que o evento empreendedor compreende cinco características: iniciativa, consolidação de recursos, gestão da organização, autonomia relativa e assunção de risco. Assim, nesta abordagem, o evento empreendedor poderia referir-se à formação de um novo negócio. Segundo eles, a ação que provoca o evento empreendedor depende de dois fatores: desejo e a viabilidade, definiram o primeiro como a atratividade pessoal de iniciar um negócio, incluindo os impactos intrapessoais e extrapessoais, e a viabilidade percebida como o grau em que alguém se sente pessoalmente capaz de iniciar um negócio, os quais combinados com a propensão para a ação refletem na intenção de agir diante de determinada alternativa. 


\section{DIMENSÃO 8 - TOMADA DE DECISÃO}

A última dimensão, denominada tomada de decisão, trata das diferenças comportamentais e estilos de gerenciamento entre gestores e empreendedores, evidenciando características próprias de como agem diante de um problema. Busenitz e Barney (1997) defendem que os empreendedores tendem a utilizar, mais frequentemente, as heurísticas no processo de decisão, além disso, apresentam um nível de otimismo mais elevado na valorização de potenciais oportunidades, mesmo sem dados objetivos para esse julgamento. Estes autores investigaram as diferenças nos processos de tomada de decisão usados por gerentes de grandes organizações e empreendedores, cujas diferenças foram examinadas em relação às heurísticas da representatividade (tendência de generalização) e ao excesso de confiança (superestimação da probabilidade de ser correto). Os resultados revelaram que havia diferenças comportamentais substanciais entre gestores de grandes organizações e empresários, sendo evidenciada a presença da heurística da representatividade (acompanhada de insensibilidade a base-rates) e do excesso de confiança em julgamentos e decisões de gestores em grandes organizações e empreendedores, ou seja, os empreendedores são propensos a serem superconfiantes e inclinados à generalizações exageradas diante das oportunidades a eles apresentadas. 


\section{DISCUSSÃO}

Na dimensão 1 depreende-se que a postura estratégica de uma organização empreendedora é evidenciada não somente pela sua tendência à assunção de riscos, às ações proativas e com orientação para agressividade competitiva, bem como pela sua confiança na inovação de produtos e serviços (COVIN; SLEVIN, 1989, COVIN; SLEVIN, 1991). O empreendedorismo organizacional tem relação com variáveis do ambiente e com a estratégia adotada pelos líderes, pois, especialmente nas pequenas empresas, líder é quem predominantemente influencia o empreendedorismo (MILLER, 1983). Por isso, é necessário que as investigações acerca deste fenômeno contemplem tanto os momentos iniciais de sua concepção quanto a pós-abertura (GARTNER, 1988).

A dimensão 2 mostra que as pesquisas sobre empreendedorismo podem ser categorizadas em dois tipos principais: estudos que abordam fatores internos (fatores motivacionais e individuais) e fatores externos (fatores contextuais e ambientais relacionados ao indivíduo). Os estudos sobre fatores internos compreendem os empreendedores como indivíduos com valores, atitudes e necessidades únicas que os conduzem e os diferenciam de não empreendedores, e sua premissa é que suas necessidades, movimentações, atitudes, crenças e valores são determinantes primários do comportamento (KOH, 1996).

Por outro lado, Brockhaus (1980) defende que as pessoas não nascem empreendedoras, mas podem se tornar. No entanto, o fato de alguns indivíduos, ao reconhecerem uma oportunidade de negócio, optarem por criar uma organização para explorá-la, enquanto outros, ao perceberem a mesma oportunidade optam por não empreender, levanta a questão sobre a possibilidade de existir um conjunto de características individuais que afeta essa decisão. Tipicamente, o empreendedor identifica oportunidades no ambiente e pesquisas vêm demonstrando que algumas características individuais são mais recorrentes quando se busca identificar futuros empreendedores, entre elas estão: necessidade de realização, autonomia /independência, histórico familiar, agressividade, poder, reco- 
nhecimento de oportunidade, inovação, independência (HORNADAY; ABOUD, 1971).

Os estudos sobre "Atitude e comportamento empreendedor" (dimensão 3) revelam que a atitude empreendedora mostra como se comportam as pessoas que são capazes de prever tendências e de antecipar mudanças, pois empreendedores assumem riscos e responsabilidades dentro da empresa (ROBINSON et al., 1991, DRUCKER, 1985), por isso, o empreen é visto como alguém que consegue transformar ideias em ações que geram lucro, especialmente quando diante de problemas que requerem novas soluções. O comportamento empreendedor impulsiona os indivíduos a agirem, porém a abordagem voltada apenas aos aspectos pessoais mostra-se insuficiente para explicar o fenômeno do empreendedorismo, portanto, é necessário compreender como o ambiente externo está estruturado na mente do futuro empreendedor (cognição social) e como este indivíduo opta por agir (SHAVER; SCOTT, 1991).

Nos estudos da dimensão 4, observa-se que o enfoque central do processo empreendedor deve ser na intenção empreendedora, uma vez que se baseia na criação de novos empreendimentos, revelando o quanto um indivíduo está comprometido em começar um novo negócio (Krueger, 1993). Evidenciam também que fatores, tais como: o contexto social, história individual, as habilidades pessoais e a personalidade, por meio da interação com o pensamento racional e intuitivo, são responsáveis por desencadear tanto a intencionalidade quanto as ações empreendedoras (BIRD, 1988). O autor leva em conta tanto os domínios individuais quanto as variáveis contextuais como responsáveis pela formação da intenção de empreender. Além disso, os modelos de Intenção Empreendedora são generalizáveis e capazes de prever a intenção de empreender, por ter condições de predizer e explicar características difíceis de serem observadas em termos de ações comportamentais (KRUEGER et al., 2000). O desejo e a viabilidade reforçam a Intenção Empreendedora.

Na dimensão 5, Mueller e Thomas (2001) concluem que a cultura nacional pode conduzir os indivíduos mais, ou menos, facilmente ao empreendedorismo, tendo em vista que algumas culturas são mais propícias 
para desenvolverem características relevantes como lócus de controle e assunção de riscos, por exemplo. O termo empreendedor, para Hamilton (2000), significa trabalhador autônomo e os fatores mais relevantes que conduzem os indivíduos ao empreendedorismo podem ser mais de caráter não pecuniário do que os retornos monetários esperados. Entre estes fatores estão o status social, a gestão da própria rotina e a satisfação pessoal com seu próprio negócio.

O construto lócus de controle foi desenvolvido na década de 60 por Rotter ao buscar explicar o que as pessoas compreendem como a fonte de controle: o próprio indivíduo (lócus interno) ou algum elemento além do indivíduo (lócus externo). A análise desta característica individual é importante, pois indivíduos com maior lócus de controle interno seriam mais propensos ao empreendedorismo do que aqueles com maior lócus de controle externo. Outra característica individual de relevo na identificação de empreendedores reside em sua disposição para assumir riscos. Stewart e Roth (2001) ressaltam que isso é imprescindível na atividade empreendedora, vis o que os resultados do estudo evidenciaram a existência de relação forte entre a disposição para assumir riscos e a propensão dos indivíduos quando se trata de explorar oportunidades.

Na dimensão 6, Simon, Houghton e Aquino (2000) investigaram viéses cognitivos dos empreendedores quanto à percepção dos riscos com os quais precisam lidar no decorrer das atividades, concluindo que há uma tendência de subestimarem os riscos reais envolvidos. Assim, consideram que, na verdade, os empreendedores não aceitam riscos altos porque tem propensão para assumi-los, mas sim porque negligenciam alguns fatores que não fazem parte do seu conhecimento. O modelo desenvolvido por Shane (2003) sugere que o processo empreendedor engloba diferentes aspectos como características individuais e oportunidades empreendedoras (descoberta e exploração). Desse modo, para compreender o empreendedorismo se faz necessária uma abordagem interdisciplinar abrangendo conhecimentos das áreas de finanças, economia, estratégia e políticas públicas, entre outras. Quanto ao papel do conhecimento, o referido autor considera que o conhecimento prévio e a experiência são determinantes na 
ação empreendedora. Penrose (1959) complementa definindo empreendedores como indivíduos com características que os diferenciam em termos de ambição, capacidade de julgamento e versatilidade. Por isso, os gerentes empreendedores exercem papel primordial nas organizações, uma vez que são dotados tanto de visão quanto de imaginação para explorarem oportunidades.

A dimensão 7 aborda aspectos a respeito da ação empreendedora tratando das teorias propostas por Schumpeter (1936) e de Shapero e Sokol (1982). Ao combinar fatores de produção eficientes com inovação, o empreendedor passa a ser o agente responsável pela criação de novos produtos, por conseguinte, os empreendedores devem inovar (SCHUMPETER, 1936). Este autor considera que a ação empreendedora tem relação com a criação de novos mercados e isso ocorre por intermédio da inovação, a qual se origina por meio da concretização do papel do empreendedor. A fim de explicar a intenção de empreender, Shapero e Sokol (1982) desenvolveram um modelo teórico que mostra como surge o evento empreendedor (surgimento de um novo negócio). Neste modelo, além do desejo e da viabilidade considerados como determinantes, outro aspecto de destaque é a propensão para a ação, pois a combinação destes evidencia a intenção de um indivíduo para agir quando nota a existência de uma oportunidade.

$\mathrm{Na}$ oitava dimensão, denominada "Tomada de decisão", ao investigarem as diferenças nos processos de tomada de decisão de gerentes de grandes organizações e de empreendedores, Busenitz e Barney (1997) observaram que diante de ambientes complexos e sem estabilidade, em termos de heurísticas da representatividade e de viés do excesso de confiança, os vieses cognitivos e as heurísticas demonstram-se orientadores eficientes nos processos de tomada de decisões dos empreendedores proporcionando a exploração de oportunidades. Além disso, os empreendedores têm maior tendência ao uso de formas não convencionais e mais flexíveis para tomarem decisões. 


\section{CONSIDERAÇÕES FINAIS}

Este estudo teve por objetivo analisar a estrutura intelectual da produção científica que fornece base para estudos referentes à propensão ao empreendedorismo por meio da análise de cocitações. Foram empregados métodos bibliométricos para analisar as publicações, identificando as produções mais citadas e demonstrando a relação entre estas publicações. Das 367 publicações sobre propensão ao empreendedorismo, a primeira ocorreu no ano de 1972, intitulada Choice in a changing world escrita por Ernest R. Alexander, motivada pelo fato de que o autor considerava que os modelos de decisão que aspiravam à generalidade (racional normativos e incrementalismo) eram fracos, pois estavam divorciados de qualquer ambiente societal ou assumiam a universalidade para uma forma de sociedade. Nas duas décadas seguintes o interesse pelo tema se manteve em declínio (década de 80 com oito publicações e década de 90 com 33 publicações), mas a partir do ano de 2000 ocorreu um aumento significativo (a primeria década com 101 publicações) e, entre 2010 e 2016 já foram publicados 223 trabalhos sobre propensão ao empreendedorismo. Os periódicos com maior número de publicações foram, respectivamente: Journal of Business Venturing (32), Small Business Economics (20), International Journal of Entrepreneurship and Small Business (11), International Entrepreneurship and Management Journal (10) e Entrepreneurship: Theory and Practice (8).

$\mathrm{Na}$ análise de cocitação contida nos 367 artigos foi possível identificar a base do conhecimento deste campo científico e observar o grau de associação entre os documentos, de acordo com a compreensão da comunidade de autores. As publicações agruparam-se em oito dimensões: empreendedorismo como processo organizacional; características do empreendedor; atitude e comportamento empreendedor; antecedentes da intenção empreendedora; locus de controle e efeitos da cultura no empreendedorismo; processos cognitivos e identificação de oportunidades; ação empreendedora; e, tomada de decisão.

Cabe destacar que, devido ao propósito da análise de cocitações, neste estudo as referências que serviram de base são mais antigas, pois são as 
que fornecem a estrutura da produção científica sobre o tema estudado. A publicação mais citada pela comunidade científica que trata de propensão ao empreendedorismo foi The Achieving Society com 113 ocorrências, obra de autoria de McClelland (1961), o qual considera que o desenvolvimento econômico ocorre por meio de uma sequência de acontecimentos, em decorrência do desejo de sucesso e, assim, há o florescimento do espírito empreendedor na sociedade.

Embora as oito dimensões identificadas no estudo, fruto da AFE, sejam convergentes ao objeto de estudo, fica claro que cada uma tem suas próprias especificidades, propiciando a construção de um arcabouço teórico passível de alicerçar estudos futuros. Evidencia-se também, que o tema em si reforça a necessidade de continuidade de investigações, cujo intuito é identificar um núcleo que contribua para o entendimento do importante papel do empreendedor na sociedade, quer seja pelas suas características, atitudes e comportamentos, pela sua capacidade de assunção de riscos e identificação de oportunidades, como também pela forma como toma decisões, sob a égide de uma cultura empreendedora. Estas são as importantes contribuições do presente artigo.

Diante destas constatações, conclui-se que embora os aspectos econômicos, sociais e ambientais, dentro e fora de organizações, amplamente citados nos artigos em pauta, tenha significado ímpar, há de se considerar que a presença, a relevância e o papel do empreendedor dotados de características psicológicas individuais distintas de outros agentes. Futuras pesquisas poderão explorar semelhanças e diferenças nas definições e operacionalidade entre os constructos presentes na literatura atual sobre futuros empreendedores (propensão ao empreendedorismo e os seus correlatos). Assim, este artigo abre perspectivas para pesquisas futuras, tendo em vista que as circunstâncias econômicas, as redes sociais, as fontes de recursos, entre outros aspectos são importantes para o empreendedorismo, mas não dissociados. 


\section{REFERÊNCIAS}

AJZEN, I. The theory of planned behavior. Organizational behavior and human decision processes, v. 50, n. 2, p. 179-211, 1991.

AJZEN, I. Constructing a TPB questionnaire: Conceptual and methodological considerations. 2002. Disponível em: http:// chuang.epage.au.edu.tw/ezfiles/168/1168/attach/20/pta_41176_7688352_57138.pdf. Acesso em: 15 jan. 2017.

ALEXANDER, E. R. Choice in a changing world. Policy Sciences, v. 3, n. 3, p. 325-337, 1972. doi.org/10.1007/BF01413686

ARAÚJO, C. A. Bibliometria: evolução histórica e questões atuais. Em questão, v. 12, n. 1, 2006.

BELLARDO, T. The use of co-citations to study science. Library Research, v. 2, n. 3, p. 231-237, 1980.

BIRD, B. Implementing entrepreneurial ideas: The case for intention. Academy of management Review, v. 13, n. 3, p. 442-453, 1988. doi.org/10.5465/AMR.1988.4306970

BRAZEAL, D. V. Organizing for internally developed corporate ventures. Journal of Business venturing, v. 8, n. 1, p. 75-90, 1993.

BROCKHAUS R. H. Risk taking propensity of entrepreneurs. Academy of management Journal, v. 23, n. 3, p. 509-520, 1980. doi.org/10.2307/255515

BROCKHAUS, R. H. The psychology of the entrepreneur. In: GASSE, Y. (Ed.). Elaborations on the psychology of the entrepreneur. Encyclopedia of entrepreneurship. Englewood Cliffs - New Jersey: Prentice-Hall, 1982.

BROCKHAUS, Robert H. Entrepreneurial folklore. Journal of Small Business Management, v. 25, n. 3, p. $1,1987$.

BORGMAN, C. L.; FURNER, J. Scholarly communication and bibliometrics. Annual review of information science and technology, v. 36, n. 1, p. 1-53, 2002.

BULL, I.; WILLARD, G. E. Towards a theory of entrepreneurship. Journal of business venturing, v. 8, n. 3, p. 183-195, 1993. doi.org/10.1.1.458.709\&rep=rep1\&type $=$ pdf

BUSENITZ, L. W.; BARNEY, J. B. Differences between entrepreneurs and managers in large organizations: Biases and heuristics in strategic decision-making. Journal of business venturing, v. 12, n. 1, p. 9-30, 1997. doi.org/10.1016/S0883-9026(96)00003-1

CHAVAN, M.; TAKSA, L.. Shifts in Intergenerational Mobility of Indian Immigrant Entrepreneurs. International Migration, v. 55, n. 1, p. 99-127, 2017. Doi:10.1111/ imig. 12303

CHELARIU, C. et al. Entrepreneurial propensity in a transition economy: exploring micro-level and meso-level cultural antecedents. Journal of Business \& Industrial Marketing, v. 23, n. 6, p. 405-415, 2008. doi.org/10.1108/08858620810894454 
CHUEKE, G. V.; AMATUCCI, M. O que é bibliometria? Uma introdução ao fórum. Internext, v. 10, n. 2, p. 1-5, 2015.

COLETA, J. A. D. A escala de lócus de controle interno-externo de Rotter: um estudo exploratório. Arquivos Brasileiros de Psicologia, v. 31, n. 4, p. 167-181, 1979.

COVIN, Jeffrey G.; SLEVIN, D. P. A conceptual model of entrepreneurship as firm behavior. Entrepreneurship theory and practice, v. 16, n. 1, p. 7-26, 1991. doi/10.1177/104225879101600102

COVIN, J. G.; SLEVIN, D. P. Strategic management of small firms in hostile and benign environments. Strategic management journal, v. 10, n. 1, p. 75-87, 1989. doi.org/10.1002/ smj. 5250100107

DRUCKER, P. F. Innovation and entrepreneurship practices and principles. New York: Harper and Row, 1985.

DRUCKER, P. F. The discipline of innovation. Harvard business review, v. 76, n. 6, p. 149157, 1998. doi.org/10.1002/lt1.40619980906

FÁVERO, L. P. L. et al. Análise de dados: modelagem multivariada para tomada de decisão. São Paulo: Campus, 2009.

FILION, L. J. Defining the entrepreneur. In: DANA, L. P. (Ed.) World encyclopedia of entrepreneurship, Cheltenham: Edward Elgar Publishing, p. 41-52, 2011.

GARTNER, W. B. "Who is an entrepreneur?" is the wrong question. American journal of small business, v. 12, n. 4, p. 11-32, 1988. doi/abs/10.1177/104225878801200401

GUEDES, V. L. S.; BORSCHIVER, S. Bibliometria: uma ferramenta estatística para a gestão da informação e do conhecimento, em sistemas de informação, de comunicação e de avaliação científica e tecnológica. In: ENCONTRO NACIONAL DE CIÊNCIA DA INFORMAÇÃO, n., 2005. Cidade. Anais.... Cidade: Instituição, 2005.v. 6, p. 1-18,

HAIR, J. F. et al. Análise multivariada de dados. Porto Alegre: Bookman Editora, 2009.

HAMILTON, B. H. Does entrepreneurship pay? An empirical analysis of the returns to self-employment. Journal of Political economy, v. 108, n. 3, p. 604-631, 2000. doi. org/10.1086/262131

HISRICH, R. D. Empreendedorismo.In: PETERS, M. P. (Ed.). Empreendedorismo. Tradução de Lene Belon Ribeiro. Cidade: Bookman Editora, 2004.

HORNADAY, J. A.; ABOUD, J. Characteristics of successful entrepreneurs. Personnel psychology, v. 24, n. 2, p. 141-153, 1971. doi.org/10.1111/j.1744-6570.1971.tb02469.x

KERLINGER, F. N. Metodologia da pesquisa em ciências sociais. São Paulo: EPU/Edusp, 1980.

KHANDUJA, D.; KAUSHIK, P. Exploring education driven entrepreneurship in engineering graduates in India. International Journal of Continuing Engineering Education and Life Long Learning, v. 19, n. 2-3, p. 256-270, 2009.doi.org/10.1504/IJCEELL.2009.025032 
KIRZNER, I. M. Competition and Entrepreneurship. Chicago: The University of Chicago Press, 1973.

$\mathrm{KOH}, \mathrm{C} . \mathrm{H}$. Testing hypotheses of entrepreneurial characteristics: A study of Hong Kong MBA students. Journal of managerial Psychology, v. 11, n. 3, p. 12-25, 1996. doi/ abs / 10.1108/02683949610113566

KRUEGER, N. The impact of prior entrepreneurial exposure on perceptions of new venture feasibility and desirability. Entrepreneurship theory and practice, v. 18, n. 1, p. 5-21, 1993. doi.org/10.1177/104225879301800101

KRUEGER JR, N. F.; BRAZEAL, D. V. Entrepreneurial potential and potential entrepreneurs. Entrepreneurship theory and practice, v. 18, n. 3, p. 91-104, 1994. doi / $10.1177 / 104225879401800307$

KRUEGER JR, N. F.; REILLY, M. D.; CARSRUD, A. L. Competing models of entrepreneurial intentions. Journal of business venturing, v. 15, n. 5-6, p. 411-432, 2000. doi. org/10.1016/S0883-9026(98)00033-0

LOPES, S. et al. A Bibliometria e a Avaliação da Produção Científica: indicadores e ferramentas. In: ACTAS DO CONGRESSO NACIONAL DE BIBLIOTECÁRIOS, ARQUIVISTAS E DOCUMENTALISTAS, n., 2012. Cidade. Anais... Lisboa: Fundação Calouste Gulbenkian, 2012.

MACHADO, R. N. Estrutura intelectual da literatura científica do Brasil e outros paises dos BRICS: uma análise de cocitação de periódicos na área de célula-tronco / Raymundo das Neves Machado. Rio de Janeiro, 2015. 364f.

MARTES, A. C. B. Weber e Schumpeter: a ação econômica do empreendedor. Brazilian Journal of Political Economy, v. 30, n. 2, p. 254-270, 2010. doi.org/10.1590/S010131572010000200005

McCAIN, K. W. Mapping economics through the journal literature: An experiment in journal cocitation analysis. Journal of the American Society for Information Science, v. 42, n. 4, p. 290, 1991. doi.org/10.1002/(SICI)1097-4571(199105)42:4<290::AID-ASI5>3.0. CO;2-9

McCLELLAND, D. C. The achieving society. Princeton, NJ: D. Van Norstrand Company, 1961.

MEDEIROS, J. M. G.; VITORIANO, M. A. V. A evolução da bibliometria e sua interdisciplinaridade na produção científica brasileira. RDBCI: Revista Digital de Biblioteconomia e Ciência da Informação, v. 13, n. 3, p. 491-503, 2015. Doi: 10.20396/rdbci.v13i3.8635791

MORAES, G. H. S. M.; IIZUKA, E. S.; PEDRO, Ms. Effects of Entrepreneurial Characteristics and University Environment on Entrepreneurial Intention. Revista de Administração Contemporânea, v. 22, n. 2, p. 226-248, 2018.

MORRIS, M. H.; LEWIS, P. S.; SEXTON, D. L. Reconceptualizing entrepreneurship: an input-output perspective. SAM Advanced Management Journal, v. 59, n. 1, p. 21, 1994. 


\section{VÂNIA MARIA JORGE NASSIF}

MILLER, D. The correlates of entrepreneurship in three types of firms. Management science, v. 29, n. 7, p. 770-791, 1983. doi.org/10.1287/mnsc.29.7.770

MINER, J. B.; RAJU, N. S. Risk propensity differences between managers and entrepreneurs and between low- and high-growth entrepreneurs: A reply in a more conservative vein. Journal of Applied Psychology, 89, p. 3-13, 2004.

MOROZ, P. W.; HINDLE, Kevin. Entrepreneurship as a process: Toward harmonizing multiple perspectives. Entrepreneurship Theory and Practice, v. 36, n. 4, p. 781-818, 2012. $\mathrm{doi} / \mathrm{abs} / 10.1111 / \mathrm{j} .1540-6520.2011 .00452 . \mathrm{x}$

MUELLER, S. L.; THOMAS, A. S. Culture and entrepreneurial potential: A nine country study of locus of control and innovativeness. Journal of business venturing, v. 16, n. 1, p. 51-75, 2001.

PENROSE, E. T. The Theory of the Growth of the Firm (with a new foreword by the author, 3rd edn). Oxford University Press: Oxford, 1995.

ROBINSON, P. B. et al. An attitude approach to the prediction of entrepreneurship. Entrepreneurship theory and practice, v. 15, n. 4, p. 13-32, 1991. doi/ $\mathrm{abs} / 10.1177 / 104225879101500405$

RODRIGUES, M. P. L. Citações nas dissertações de mestrado em ciência da informação. Ciência da Informação, Brasília, v. 11, n. 1, p. 35-59, 1982.

ROTTER, J. B. Generalized expectancies for internal versus external control of reinforcement. Psychological monographs: General and applied, v. 80, n. 1, p. 1, 1966. doi. org/10.1037/h0092976

SHAVER, K. G.; SCOTT, L. R. Person, process, choice: The psychology of new venture creation. Entrepreneurship theory and practice, v. 16, n. 2, p. 23-46, 1992. doi/ abs/10.1177/104225879201600204

SCHUMPETER, J. A. The theory of economic development: An inquiry into profits, capital, credit, interest, and the business cycle. Cambridge: Harvard University Press, 1936.

SHANE, S. A. A general theory of entrepreneurship: The individual-opportunity nexus. Cheltenham: Edward Elgar Publishing, 2003.

SHANE, S.; VENKATARAMAN, S. The promise of entrepreneurship as a field of research. Academy of management review, v. 25, n. 1, p. 217-226, 2000.doi.org/10.5465/ AMR.2000.2791611

SHANE, S.; LOCKE, E. A.; COLLINS, C. J. Entrepreneurial motivation. Human resource management review, v. 13, n. 2, p. 257-279, 2003. doi.org/10.1016/S1053-4822(03)00017-2

SHAPERO, A.; SOKOL, L. The social dimensions of entrepreneurship. In C. A. Kent, D. L. Sexton, \& K. H. Vesper (Eds.). Encyclopedia of entrepreneurship, pp. 72-90. Englewood Cliffs, NJ: Prentice Hall, p. 72-90, 1982.

SHAVER, K. G.; SCOTT, L. R. Person, process, choice: The psychology of new 
venture creation. Entrepreneurship theory and practice, v. 16, n. 2, p. 23-46, 1992.doi/ abs/10.1177/104225879201600204

SIMON, M.; HOUGHTON, S. M.; AQUINO, K. Cognitive biases, risk perception, and venture formation: How individuals decide to start companies. Journal of business venturing, v. 15, n. 2, p. 113-134, 2000. doi.org/10.1016/S0883-9026(98)00003-2

SMALL, H. Co-citation in the scientific literature: A new measure of the relationship between two documents. Journal of the Association for Information Science and Technology, v. 24, n. 4, p. 265-269, 1973. doi.org/10.1002/asi.4630240406

SMIRAGLIA, R. P. ISKO 11's diverse bookshelf: An editorial. Knowledge organization, v. 38, n. 3, p. 179-186, 2011.

SOUZA VANZ, S. A.; STUMPF, I. R. C. Procedimentos e ferramentas aplicados aos estudos bibliométricos. Informação \& Sociedade, v. 20, n. 2, 2010.

STEWART JR, W. H.; ROTH, P. L. Risk propensity differences between entrepreneurs and managers: A meta-analytic review. Journal of applied psychology, v. 86, n. 1, p. 145, 2001. doi.org/10.1037/0021-9010.86.1.145

STEWART JR, W. H. et al. A proclivity for entrepreneurship: A comparison of entrepreneurs, small business owners, and corporate managers. Journal of Business venturing, v. 14, n. 2, p. 189-214, 1999. doi.org/10.1016/S0883-9026(97)00070-0

SUŠANJ, Z.; JAKOPEC, A.; MILJKOVIĆ KREČAR, I. Verifying the model of predicting entrepreneurial intention among students of business and non-business orientation. Management: Journal of contemporary management issues, v. 20, n. 2, p. 49-69, 2015.

THEÓPHILO, C. R. Algumas reflexões sobre pesquisas empíricas em contabilidade. Caderno de Estudos, n. 19, p. 1-8, 1998.

WHITE, H. D.; GRIFFITH, B. C. Author cocitation: A literature measure of intellectual structure. Journal of the Association for Information Science and Technology, v. 32, n. 3, p. 163$171,1981$.

WILLIAMS, B.; ONSMAN, A.; BROWN, T. Exploratory factor analysis: A five-step guide for novices. Australasian Journal of Paramedicine, v. 8, n. 3, 2010.

WHITE, H. D.; GRIFFITH, B. C. Author cocitation: A literature measure of intellectual structure. Journal of the Association for Information Science and Technology, v. 32, n. 3, p. 163171, 1981. doi.org/10.1002/asi.4630320302

YASIN, M. Entrepreneurial effectiveness and achievement in Arab culture: New evidence to rekindle interest in an old predictor. Journal of Business Research, v. 35, n. 1, p. 69-77, 1996. doi.org/10.1016/0148-2963(95)00050-X 
VÂNIA MARIA JORGE NASSIF

DADOS DOS AUTORES

\section{LORENI MARIA DOS SANTOS BRAUM lorenibraum@hotmail.com}

Doutoranda em Administração pela UNINOVE

Instituição de vinculação: Universidade Nove de Julho

São Paulo/SP - Brasil

Áreas de interesse em pesquisa: Características Psicológicas do Empreendedor; Ensino e Pesquisa em Administração e em Ciências Contábeis.

* Rua Presidente Costa e Silva, 2370 Centro Marechal Cândido Rondon/PR 85960-000

\section{VÂNIA MARIA JORGE NASSIF vania.nassif@gmail.com}

Doutora em Administração pela UPM

Instituição de vinculação: Universidade Nove de Julho

São Paulo/SP - Brasil

Áreas de interesse em pesquisa: Empreendedorismo, Comportamento Empreendedor, Características Psicológicas do Empreendedor. 